\title{
Man-hour Estimation Model based on Standard Operation Unit for Flexible Manufacturing System
}

\author{
Zhenggeng $\mathrm{Ye}^{1, *}$, Jiachao Cui ${ }^{1}$ and Fuli Zhou ${ }^{2}$ \\ ${ }^{1}$ The 713th Research Institute of China Shipbuilding Industry Corporation, Zhengzhou, China \\ ${ }^{2}$ Department of Industrial Engineering, Chongqing University, Chongqing China \\ Corresponding Email: yezhenggeng@139.com
}

\begin{abstract}
In flexible manufacturing system, the estimation of man-hour is a difficult problem because of its production-diversity. To explore a more effective method, this paper tried to estimate man-hour from the perspective of operation's character by establishing standard operation unit (SOU) in this paper. A method of parameterizing the SOU is proposed, and a new man-hour estimation model is established on the basis of SOU. At last, this paper verified the effectiveness of this method by the operation of large-scale welding parts.
\end{abstract}

\section{Introduction}

The diversity of productions that clients need promoted the enterprise transforming gradually from the standardization production to customized production[1, 2]. In this environment, the flexible manufacturing system is increasingly accepted and used in manufacturing factory which can achieve the producing of more than one production line at the same time[3]. With these advantages, the problems of complicated management, such as man-hour estimation and shop scheduling, also puzzled the enterprises. Man-hour is the basic data for enterprise to finish production management, but it is difficult to find a quick and effective way to estimate it for a long time because of its production-diversity. To solve this problem, XIAO Ying-jiao and Zhou Yu-jie put forward a new method to estimate man-hour based on the group technology and modular[4, 5]. They divided the productions into modules and established different kind of time modules based on the character of productions, which provides a new idea for the estimation of man-hour. In the following study, YANG Qing-qing divided the process time into three time modules: static time, flexible time and unique time, which is also on the basis of product's structure[6]. This method is effective to estimate man-hour, but it also cannot quickly finishing the estimating when a large number of new structure products are putted into producing. In order to get rid of product structure's constraints on man-hour estimation, it is necessary to explore the estimation method from the perspective of the operation.

To study virtual man`s action, LU Xiao-jun presented a virtual human`s action database on the basis of action unit level and motion element level, who began to study human behaviour from a hierarchical perspective[6, 7]. Later, to study virtual human's action models in virtual maintenance, CHANG Gao-xiang separated the process of maintenance into three courses and established three corresponding straticulate action modes[8]. He fully implemented studying operating behavior in a hierarchical perspective. With further research of hierarchical model, the study of Parameterized Action Representation (PAR) also made great progress. Norman I. Badler and Ramamani Bindiganavale presented the model of PAR by studying how to bridge the gap between natural language instructions and the virtual agents, and this opens up a path to parametric research on operation behaviour [9-11]. Based on these achievements, PAR is used into study of virtual maintenance. WANG Feng-chan presented the Maintenance Task Decomposition Model and Actions Database based on the PAR and Intelligent Virtual Maintenance Training System in Delmia environment[12]. All of these is the good foundation for the research of man-hour estimation in operation perspective.

\section{Standard operation unit generation by work breakdown method}

\subsection{Work breakdown}

In previous researches, operation is usually studied from the perspective of process. In Flexible Manufacturing System (FMS), one operation process will not comply with other products due to the difference of productions` structure and material. In production, operation is usually completed step by step and consisted of different discrete movement modules. 
This paper decomposed the operation to modules, and summarized their analogous property and established the modular model of operation. This part will analyse the decomposing of operation based on Work Breakdown Structure.

Work Breakdown Structure (WBS) comes from project management, which is an effective method to decompose project. Through this method, work of project can be divided into more flexible and manageable units to improve management efficiency[13]. Based on this advantages, WBS has been used to study operation process of manufacturing. Chenqiang(2009) proposed the theory of Product-oriented Work Breakdown Structure(PWBS) by studying the application of WBS to Shipbuilding Industry, and decomposed shipbuilding-operation into different modules on the basis of Similarity Principle and Group Technology[14]. In this paper, the ideology of WBS is also used to study the operation process to acquire the standard operation unit of FMS.

Based on WBS, this paper builds a hierarchical model to describes the manufacturing process of products by three class: process, operation unit and therblings (Figure 1). In this model, process is a stage of a product's manufacturing, which is defined as a continuous operation of a part or a group of parts by one operator or a group of operators on one device. Operation unit is the functional module of process. Different operation units can finish different function, and the goal of process will be achieved when they are combined together. Therbling is the basic element of operation and this paper will employs the therblings of MOD to analyse the operation unit. In addition, the operation method will be different in different manufacturing technology which will lead to the difference of therblings and operation unit, so the hierarchical model of product is not one and only. So this paper will study operation characteristics, summarize operation unit and establish the hierarchical model on the basis of the given manufacturing technology.

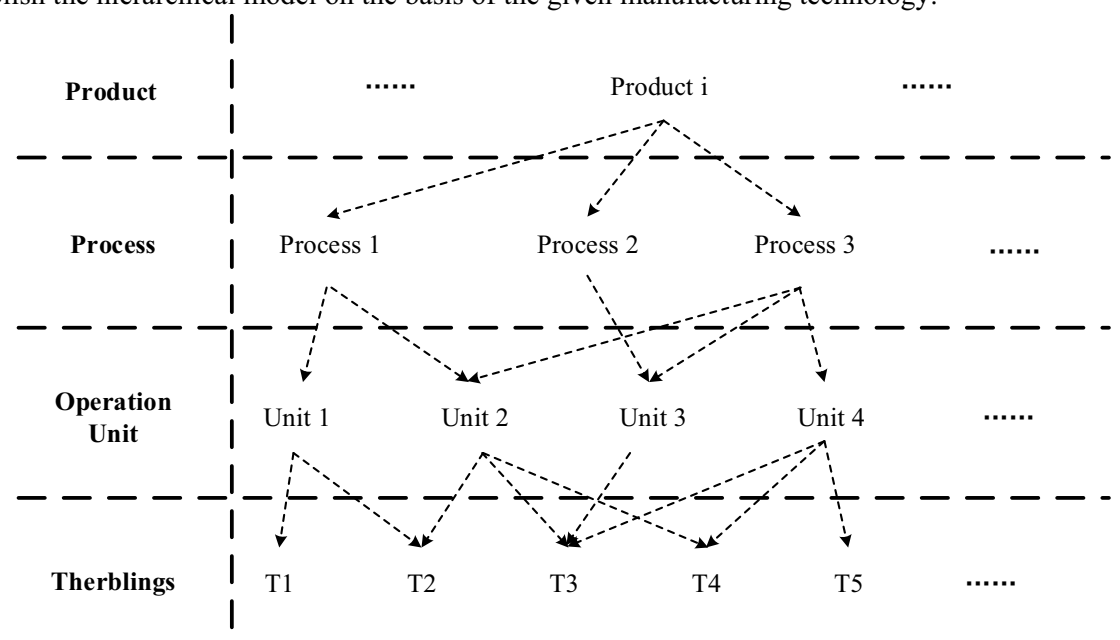

Fig. 1. Hierarchical Model of Manufacturing Process.

\subsection{Character extraction of the operation unit}

Operation unit is universal operation modular of operating process, which is extracted by work breakdown. This paper defined it as the portfolios and configurations of therblings that operators made to parts for a special operation goal. Generally, an operation unit may have the following properties (Figure 2):

- Including three key objects: operator, part and tool. Operator is the executant of the operation unit, part is the receptor.

- Purposiveness: the operation unit should have operation semantics and be finished for a special purpose of the process. In manufacturing, the purpose is the natural language instruction of process file. But therblings don 't have the operation semantics, which only represent the moving or turning of body.

- Connection: To achieve the special operation goal, these therblings must be connected. If the therblings of the operation unit are spaced, the goal will not be achieved.

- Order: therblings used in the operation unit obeys special order. Because the same sets of therblings which have different orders will be operated for different goal, they are different operation units. Similarly, the operation units will be also operated in order to finish the content of process.

- Time: the achievement of operation unit needs time, it is not instantaneous. 


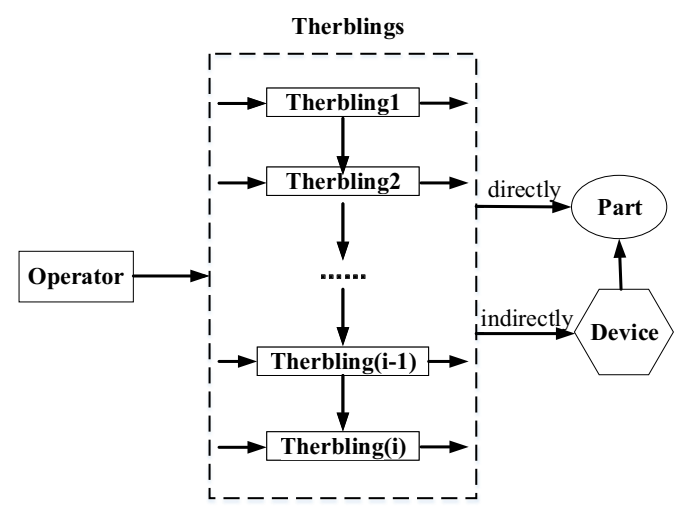

Fig. 2. Operation Unit Model.

\subsection{Standard operation unit based on three-tuple model}

Based on the above analysis, this paper proposed the concept of standard operation unit (SOU) to describe the universal character of operation unit. SOU is defined as the set of therglings that the operator finished for one purpose over a period of time, which can be used to describe the character of similar operations in the given manufacturing environment. Considering the natural language semantics of operations, this paper classified and defined the frequently-used operations in manufacturing environment, and built the SOU database. SOU can be classified into universal SOU that will be used by many kinds of process and special SOU that will be used by one kind of process. SOU database is an open database which can add new SOU according to the actual production situation. Some of the SOU is listed in Table 1.

Table 1. Classification and definition SOU Database.

\begin{tabular}{|c|c|c|}
\hline Classification & Name & Definition \\
\hline \multirow{4}{*}{$\begin{array}{c}\text { Universal } \\
\text { SOU }\end{array}$} & $\begin{array}{l}\text { Getting } \\
\text { Parts }\end{array}$ & $\begin{array}{l}\text { transport parts from } \\
\text { storage area to } \\
\text { operating area }\end{array}$ \\
\hline & Measuring & $\begin{array}{l}\text { check the size of } \\
\text { parts }\end{array}$ \\
\hline & Fixing & $\begin{array}{l}\text { fasten parts securely } \\
\text { in device }\end{array}$ \\
\hline & $\ldots$ & $\ldots$ \\
\hline \multirow{4}{*}{$\begin{array}{l}\text { Special } \\
\text { SOU }\end{array}$} & Welding & $\begin{array}{l}\text { join metal pieces or } \\
\text { parts together by } \\
\text { heating the surfaces }\end{array}$ \\
\hline & Assembling & $\begin{array}{l}\text { fit the component } \\
\text { parts of a machine } \\
\text { or other object } \\
\text { together }\end{array}$ \\
\hline & Turning & $\begin{array}{l}\text { shape parts on a } \\
\text { lathe }\end{array}$ \\
\hline & $\cdots$ & \\
\hline
\end{tabular}

To parameterize SOU, this paper builds a three-tuple model to describe it:

$$
\mathrm{U}=[\mathrm{O}, \mathrm{D}, \mathrm{Th}]
$$

Where:

$\mathrm{O}$ is the set of operators who maybe use this standard operation unit. For different kind of operators, their labour intensity is different, so they should be given different allowance rates for the same SOU.

$\mathrm{D}$ is the set of devices or tools used in the operation unit. If different devices or tools can be used for the same SOU, operators will need different degree of effort to finish it, so different hour coefficient should be assigned to different devices or tools.

Th is the set of basic therblings which used in the operation unit. This paper used the Therblings of MOD method to describe the operation and estimate the basic working hour. 
For one SOU, the parameterized representation model can be established:

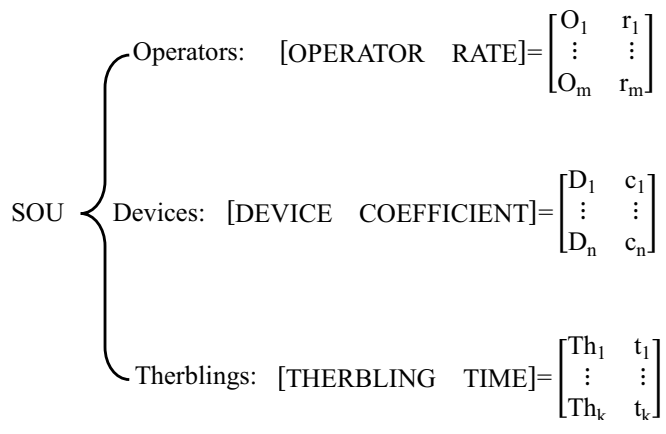

\section{Man-hour estimation model}

\subsection{Hour calculation based on SoU}

Based on above analysis, therblings are the basic elements of the SOU, which can be regarded as the combination of the different therblings portfolio. In order to identify the working hour of flexible operation for multi-specification and small-batch production in job shop, this paper proposed an estimation model integrating modularized hour unit and SOU portfolios. First, process of historical products was collected in this model and was decomposed into some operation units. Then the character of operation will be analyzed and the SOU was extracted which will constitute the SOU database. When new parts are designed, technologist analyzes their process, adopts the SOU from the database and makes sure the parameters of SOU. At last, the man-hour of SOU and process will be calculated on the basis them. Figure 3.

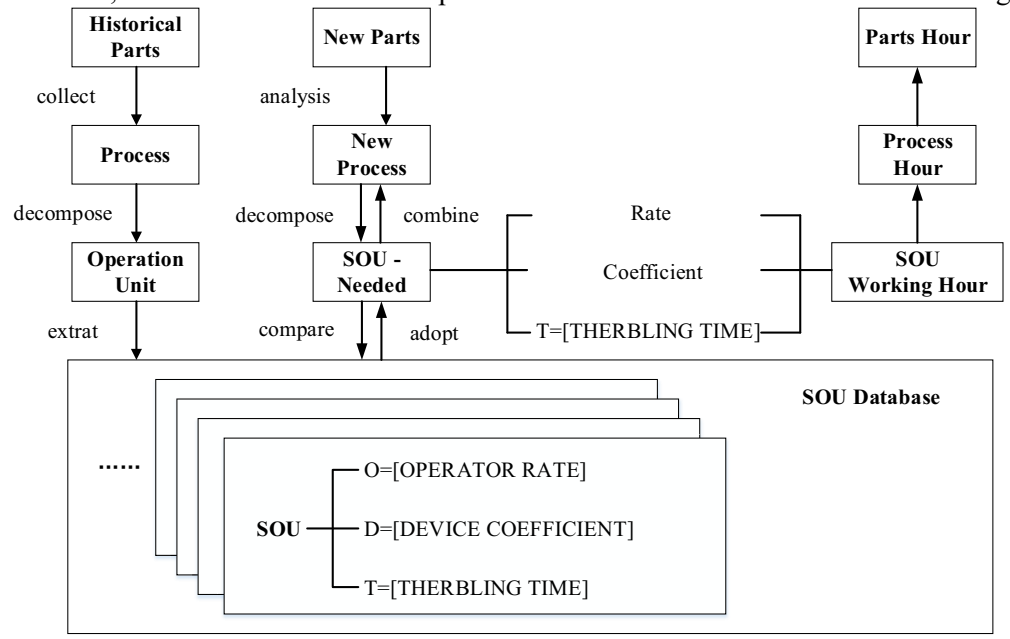

Fig. 3. Man-hour estimation process.

\subsection{Man-hour estimation model by SOU portfolios}

For one SOU, it can be parameterized as the following three matrices:

$$
\begin{aligned}
& \text { OPERATOR: [OPERATOR RATE] }=\left[\begin{array}{cc}
\mathrm{O}_{1} & \mathrm{r}_{1} \\
\vdots & \vdots \\
\mathrm{O}_{\mathrm{m}} & \mathrm{r}_{\mathrm{m}}
\end{array}\right] \\
& \text { DEVICE: [DEVICE COEFFICIENT] }=\left[\begin{array}{cc}
D_{1} & c_{1} \\
\vdots & \vdots \\
D_{n} & c_{n}
\end{array}\right] \\
& \text { THERBLING: [THERBLING TIME] }=\left[\begin{array}{cc}
\mathrm{Th}_{1} & \mathrm{t}_{1} \\
\vdots & \vdots \\
\mathrm{Th}_{\mathrm{k}} & \mathrm{t}_{\mathrm{k}}
\end{array}\right]
\end{aligned}
$$

$\mathrm{R}$ is the set of allowance rates of different operations, and their values can be calculated based on different industry standards. C is the coefficients of different devices or tools, which represents the degree of difficulty to finish the SOU. 
This paper defined the difficulty degree of device and tool`s operation in five class. The definition and value of coefficient is in table 2 .

Table 2. Class of Device`s Difficulty Degree.

\begin{tabular}{|c|c|c|}
\hline Class & Value & Definition \\
\hline I & {$[0,0.01]$} & no device/Very easily \\
\hline II & $(0.01,0.03]$ & Easily \\
\hline III & $(0.03,0.06]$ & Slightly difficultly \\
\hline IV & $(0.06,0.08]$ & Difficultly \\
\hline V & $(0.08,0.09]$ & Very difficultly \\
\hline
\end{tabular}

$\mathrm{O}$ and $\mathrm{D}$ is the set of SOU's operators and devices. If operator $\mathrm{i}$ and device $\mathrm{j}$ is used in SOU, $O_{i}=1, D_{j}=1$; else the value is 0 . Assume that one operation only included operator $i$ and device $j$, then the matrix $\mathrm{O}$ and $\mathrm{D}$ will be represented as:

$$
\mathrm{O}=\left[\begin{array}{c}
\mathrm{O}_{1} \\
\vdots \\
\mathrm{O}_{\mathrm{i}-1} \\
\mathrm{O}_{\mathrm{i}} \\
\mathrm{O}_{\mathrm{i}+1} \\
\vdots \\
\mathrm{O}_{\mathrm{m}}
\end{array}\right]=\left[\begin{array}{c}
0 \\
\vdots \\
0 \\
1 \\
0 \\
\vdots \\
0
\end{array}\right] ; \quad \mathrm{D}=\left[\begin{array}{c}
\mathrm{D}_{1} \\
\vdots \\
\mathrm{D}_{\mathrm{j}-1} \\
\mathrm{D}_{\mathrm{j}} \\
\mathrm{D}_{\mathrm{j}+1} \\
\vdots \\
\mathrm{D}_{\mathrm{n}}
\end{array}\right]=\left[\begin{array}{c}
0 \\
\vdots \\
0 \\
1 \\
0 \\
\vdots \\
0
\end{array}\right]
$$

Then the allowance rate $\mathrm{r}$ of the operator and the coefficient $\mathrm{c}$ of the device is:

$$
\begin{aligned}
& r=O^{T} R \\
& c=D^{T} C
\end{aligned}
$$

Th is the set of therblings that the SOU uses and $\mathrm{T}$ is the set of their time. For one therbling $\mathrm{i}, \mathrm{Th}_{i}$ is the frequency that it is used in the SOU and $t_{i}$ is its time. So the basic time $T_{b}$ of SOU is:

$$
t_{b}=T h^{T} T
$$

So the working hour of SOU can be estimated by the following formula:

$$
\begin{gathered}
\text { time }=(1+r) \times(1+c) \times t_{b} \\
=\left[1+\left(O^{T} R\right)\right] \times\left[1+\left(D^{T} C\right)\right] \times\left(T h^{T} T\right)
\end{gathered}
$$

\section{Case study}

This paper takes the production of large-scale welding parts as the case to analyse the SOU in company G. The welding parts of company $\mathrm{G}$ usually have four process: splicing of components, welding, boring and drilling. This paper will estimate the working hour of spicing through analysing the SOU. The process of splicing can be decomposed into four SOUs: Getting parts, measuring, assembling, point-welding.

Getting parts: it is the operation to transport parts from storage area to operating area, and its parameterized representation in this manufacturing environment is

$$
\begin{aligned}
& \text { OPERATOR: [OPERATOR } \\
& \text { RATE] }]= \\
& {\left[\begin{array}{cc}
\text { welder } & 0.2 \\
\text { boring machine operator } & 0.05 \\
\text { benchwork } & 0.1
\end{array}\right]}
\end{aligned}
$$

DEVICE: $[$ DEVICE COEFFICIENT $]=[$ crane 0.02]

The therblings used in this SOU include 6 kinds (table 3), that is W5, M4, M3, G1, P1 and P0.so Th and T is:

Table 3. Therblings of Getting Parts.

\begin{tabular}{|c|c|c|c|}
\hline Number & Movement & Therblings & $\begin{array}{c}\text { Frequ } \\
\text { ency }\end{array}$ \\
\hline 1 & Walking & W5 & 5 \\
\hline 2 & $\begin{array}{c}\text { Grabbing } \\
\text { crane }\end{array}$ & M4G1 & 1 \\
\hline 3 & Hooking part & M4G1M3P1 & 1 \\
\hline 4 & Transporting & W5 & 5 \\
\hline 5 & $\begin{array}{c}\text { Taking off } \\
\text { hook }\end{array}$ & M4G1M3P0 & 1 \\
\hline
\end{tabular}




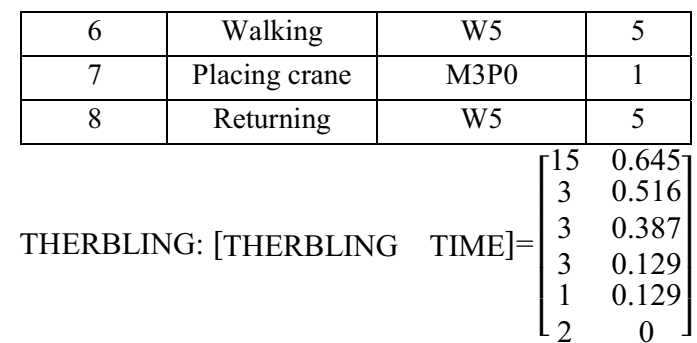

For the splicing, the operation of getting parts includes the operator welder and device crane, so the $\mathrm{O}$ and $\mathrm{D}$ is:

$$
\mathrm{O}=\left[\begin{array}{l}
\mathrm{O}_{1} \\
\mathrm{O}_{2} \\
\mathrm{O}_{3}
\end{array}\right]=\left[\begin{array}{l}
1 \\
0 \\
0
\end{array}\right] ; \mathrm{D}=\left[\mathrm{D}_{1}\right]=[1]
$$

So the allowance rate $\mathrm{r}$ of the operator, the coefficient $\mathrm{c}$ of the device and the basic time respectively is:

$$
\begin{aligned}
\mathrm{r}=\mathrm{O}^{\mathrm{T}} \mathrm{R}=\left[\begin{array}{lll}
1 & 0 & 0
\end{array}\right] \times\left[\begin{array}{c}
0.2 \\
0.05 \\
0.1
\end{array}\right]=0.2 \\
\mathrm{c}=\mathrm{D}^{\mathrm{T}} \mathrm{C}=[1] \times[0.02]=0.02 \\
\mathrm{t}_{\mathrm{b}}=\mathrm{Th}^{\mathrm{T}} \mathrm{T}=\left[\begin{array}{llllll}
15 & 3 & 3 & 3 & 1 & 2
\end{array}\right] \times\left[\begin{array}{c}
0.645 \\
0.516 \\
0.387 \\
0.129 \\
0.129 \\
0
\end{array}\right]=4.473 \mathrm{~s}
\end{aligned}
$$

so the time of getting parts is:$$
\text { time }_{1}=(1+\mathrm{r}) \times(1+\mathrm{c}) \times \mathrm{t}_{\mathrm{b}}=[1+0.2] \times[1+0.02] \times 4.473=5.47 \mathrm{~s}
$$

Similarly, the time of measuring, assembling and point-welding can be calculated:

And the time of splicing one part is:

$$
\begin{aligned}
\text { time }_{2} & =2.84 \mathrm{~s} \\
\text { time }_{3} & =7.25 \mathrm{~s} \\
\text { time }_{4} & =4.53 \mathrm{~s}
\end{aligned}
$$

$$
\text { time }=\text { time }_{1}+\text { time }_{2}+\text { time }_{3}+\text { time }_{4}=20.09_{\mathrm{S}}
$$

\section{Conclusions}

Estimation of man-hour from the perspective of operation has a wide applicability. To establish this new man-hour model, this paper used the hierarchical model to analyse the operation process and built the parameterized operation representation model, which provides technology support to quickly obtaining working hour data in flexible manufacturing environment. As the technology continues to mature, it will also provide the technology support for the digital and intelligent manufacturing in the future.

\section{References}

1. D. C. SUN, H. B. SHI, W. 1. SHANG, C. LIU, COMPUT. INTEGRA. MANUF. SYS. 5, 10(2013).

2. J. J. BAI, Y. G. GONG, N.-S. WANG, D. D. TANG,COMPUT. INTEGRA. MANUF. SYS. 2, 8(2009).

3. C. LI, S. LI, Y. P. FENG, G. RONG, J. SHANGHAI JIAOTONG U. 49, 6(2015).

4. Y. J. Xiao, Y. L. Chen, Y. J. Zhou, Application Research of Computers. 28, 4(2011).

5. Y. J. Zhou, Y. L. Chen, N. Cao, X. Z. Lu, WORLD SCI-TECH R\&D. 34,5( 2012).

6. Q. Q. Yang, Y. L. Chen, X. Z. Lu, Application Research of Computers. 29, 5(2012).

7. X. J. Lu, Y. Li, H. G. He, Computer Simulation. 23, 4(2006).

8. G. X. Chang, X. G. Xu, L. Zhang, JOURNAL OF ENGINEERING GRAPHICS. 32, 5(2011).

9. N. Badler, R. Bindiganavale, J. Allbeck, W. Schuler, L. Zhao, S. J. Lee, H. Shin, M. Palmer, AAAI Spring Symposium, 20,5(2000).

10. N. Badler, R. Bindiganavale, Embodied Conversational Agents, 9(2000).

11. R. Bindiganavale, University of Pennsylvania Scholarly Commons. 124(2000).

12. F. C. Wang, Y. Z. Sun, JOURNAL OF GRAPHICS. 34, 7(2013).

13. Q. Chen, S. Haung, SHIPBUILDING OF CHINA. 44, 13(2003).

14. A. Guide, PMBOK, 2013. 